\title{
Soluble and Endogenous Secretory Receptors for Advanced Glycation End Products in Threatened Preterm Labor and Preterm Premature Rupture of Fetal Membranes
}

\author{
Rafal Rzepka, ${ }^{1}$ Barbara Dołegowska, ${ }^{2}$ Aleksandra Rajewska, ${ }^{1}$ \\ Sebastian Kwiatkowski, ${ }^{1}$ Daria Sałata, ${ }^{2}$ Marta Budkowska, ${ }^{2}$ Leszek Domański, ${ }^{3}$ \\ Wioletta Mikolajek-Bedner, ${ }^{1}$ and Andrzej Torbé ${ }^{1}$ \\ ${ }^{1}$ Department of Obstetrics and Gynecology, Pomeranian Medical University, 70-204 Szczecin, Poland \\ ${ }^{2}$ Department of Laboratory Diagnostics and Molecular Medicine, Pomeranian Medical University, 70-204 Szczecin, Poland \\ ${ }^{3}$ Department of Nephrology, Transplantology and Internal Medicine, Pomeranian Medical University, 70-204 Szczecin, Poland
}

Correspondence should be addressed to Rafał Rzepka; rafalrz123@gmail.com

Received 6 February 2015; Accepted 19 March 2015

Academic Editor: Igor Hudic

Copyright (C) 2015 Rafał Rzepka et al. This is an open access article distributed under the Creative Commons Attribution License, which permits unrestricted use, distribution, and reproduction in any medium, provided the original work is properly cited.

The aim of the study was to compare sRAGE and esRAGE plasma levels in pregnant women with (A) threatened premature labor $(n=41)$, (B) preterm premature rupture of membranes $(n=49)$, and $(\mathrm{C})$ preterm rupture of membranes at term $(n=48)$. The relationship between these and classic intrauterine infection markers and the latent time from symptoms up to delivery depending on RAGE's concentration were investigated. In groups A and B, a positive correlation was found between plasma sRAGE and latent time $(r=0,422 ; p=0,001 ; r=0,413, p=0,004$, resp.). High prognostic values were found in both groups for plasma sRAGE concentration and the latent time from symptoms up to delivery. Groups B and C presented higher levels of esRAGE than group A $(526,315 \pm 129,453 \mathrm{pg} / \mathrm{mL}$ and $576,212 \pm 136,237 \mathrm{pg} / \mathrm{mL}$ versus $485,918 \pm 133,127 \mathrm{pg} / \mathrm{mL}, p<0,05)$. The conclusion is that sRAGE concentration can be a favorable prognostic factor in the presence of symptoms of threatened premature labor. Higher esRAGE plasma level in case of the rupture of membranes in mature and premature pregnancy suggests its participation in fetal membranes destruction.

\section{Introduction}

Preterm labor is defined as a birth of a newborn that occurs between 22 nd and 37 th week of gestation. Some $30-35 \%$ of all premature labors are iatrogenic, due to maternal or fetal indications, while the other $40-65 \%$ complete spontaneously in the consequence of preterm uterine contractility or membrane rupture [1]. Preterm end of pregnancy is the most common cause of morbidity and mortality of the newborns as well in the United States as in Europe $[1,2]$. Despite the significant development of perinatal medicine in recent years, the prevalence of premature birth has not decreased and it still remains $10-20 \%$. Many factors have been hypothesized as pathogenic for premature labor, but the activation of maternofetal inflammatory response, leading to uterine activity or preterm premature rupture of membranes (pPROM), is believed to be the most corresponding to contemporary knowledge [3].

Most of investigators consider preterm labor as an acute obstetric disease related to ascending bacterial infection of lower pole of membranes with exogenic or endogenic microbes, with subsequent rapid maternal and fetal immunologic response [4-7]. In women diagnosed with chorioamnionitis and premature labor increased plasma levels of some pathogen-associated molecular patterns (PAMPs), such as interleukin-1 beta (IL-1 $\beta$ ), calcium binding protein A5 (S100A5), prolyl 4-hydroxylase alpha polypeptide 2 (P4HA2), interleukin-6 (IL-6), interleukin-8 (IL-8), lipopolysaccharides (LPS), tumor necrosis factor-alpha (TNF- $\alpha$ ), and Creactive protein (CRP), were discovered [8-11]. Yet, in some 
cases of high PAMPs plasma level in the pregnant, there were no observable symptoms of preterm labor. For this reason present studies on preterm labor pathogenesis focus on the evaluation of chronic inflammation as the predisposing factor for the occurrence of acute intrauterine infection with preterm birth as an outcome.

In 2007 Oppenheim et al. postulated an introduction of the new concept of alarmines to medical nomenclature [12]. Intracellular alarmines, also called damage-associated molecular patterns (DAMPs), can influence immunologic response via toll-like receptors (TLR) and receptors for advanced glycation end products (RAGE) as well as by direct activation of cytokines synthesis in neutrophils and macrophages [13]. The group of the most thoroughly investigated alarmines includes high-mobility group box-1 (HMGB-1), heat shock proteins (HSP), with HSP70 particularly among them, S100A5 protein, hepatoma-derived growth factor (hdgf), IL- $1 \alpha$, and uric acid [14-17]. The DAMPs effect is connected with the activation of nonspecific receptors, mainly RAGEs and TLRs. The interaction between RAGE and its ligand yields intensification of oxidative stress not only via NADPH oxidase activation, but also via some transcription activating factors such as nuclear factor kappa-B $(\mathrm{NF} \kappa \mathrm{B})$ and mitogen-activated protein kinase (MAPK) [18]. After its release, activated $\mathrm{NF} \kappa \mathrm{B}$ reaches the nucleus to turn on the expression of genes of cytokines like tumor necrosis factor $\alpha$ (TNF $\alpha$ ), IL-1, and IL- 6 and those of adhesive proteins, with vascular cell adhesive molecule-1 (VCAM-1) and intercellular adhesive molecule-1 (ICAM-1) among them, which participate in the inflammatory process [19]. The RAGE-mediated inflammatory response can be modulated by specific negative forms of these receptors, including dominant negative receptors for advanced glycation end products (dsRAGE) and, present in circulating blood, soluble receptors for advanced glycation end products (sRAGE) as well as endogenous secretory receptors for advanced glycation end products (es-RAGE).

High levels of sRAGE are proven to reduce systemic inflammatory response, improving the course and the prognosis in some diseases involving endogenous inflammation [20-25].

From the hypothesis claiming protective effect of negative RAGE forms the question emerges whether the concentration of soluble forms of the aforementioned receptors in the pregnancy can have an impact on the prevalence of preterm labor as a consequence of spontaneous uterine contractility or preterm premature rupture of membranes.

\section{Objectives}

The objectives of this study are as follows:

(1) calculation and comparison of sRAGE and esRAGE plasma levels in three groups of pregnant women diagnosed with threatened premature labor, preterm premature rupture of membranes, and preterm rupture of membranes at term,

(2) assessment of the relationship between negative RAGE forms and classic intrauterine infection markers,
(3) evaluation of pregnancy duration from the occurrence of threatened premature labor symptoms up to delivery, depending on RAGE concentration,

(4) evaluation of pregnancy duration from the rupture of membranes until delivery, depending on RAGE concentration.

\section{Materials and Methods}

The study was conducted in the Department of Obstetrics and Gynecology and in the Department of Laboratory Diagnostics and Molecular Medicine of Pomeranian Medical University from 29/10/2012 to 30/06/2014. 138 women between 22nd and 41st week of gestation were included and subsequently divided into three groups. Group A contained 41 women between 22nd and 36th week of gestation, presenting symptoms of threatened premature labor. Group B enclosed 49 participants between 22 nd and 36 th week of gestation with preterm premature rupture of membranes. Group C brought together 48 pregnancies with the evidence of preterm rupture of membranes but lacking in uterine contractions, who completed 37 th week of gestation.

The detailed characteristics of study groups is shown in Table 1 and the inclusion criteria are listed in Table 2.

Not later than two hours after admission to the department, peripheral maternal blood was sampled from the ulnar vein and then treated with dipotassium ethylenediaminetetraacetic acid (EDTA-K ${ }_{2}$ ). After centrifugation of the whole sample (10 minutes, $5000 \mathrm{rps}$ ), obtained plasma samples were stored at $-80^{\circ} \mathrm{C}$ until sRAGE and esRAGE concentration analyses were performed. Immunoassay methods were used to sRAGE and esRAGE calculations. Human sRAGE ELISA (Bio Vendor Research and Diagnostic Products) is a sandwich enzyme immunoassay for quantitative measurement of human sRAGE. Calibration range for sRAGE is 50$3200 \mathrm{pg} / \mathrm{mL}$, with the limit of detection at 19,2 pg/mL. Human esRAGE ELISA (Cusabio, CSB-E15773h) is analogically a sandwich enzyme immunoassay for quantitative measurement of human esRAGE. Calibration range for esRAGE is $0,625 \mathrm{ng} / \mathrm{mL}-40 \mathrm{ng} / \mathrm{mL}$, with the limit of detection at $0,156 \mathrm{ng} / \mathrm{mL}$. Coefficients of variation (CV) for the assays of sRAGE and esRAGE are shown in Table 3.

All women included in the study had also determined white blood cells count and neutrophils percentage in venous blood and plasma level of C-reactive protein. In the participants in groups A and B the ultrasound cervical length was assessed with a vaginal probe placed in the vestibule of the vagina. The arithmetic mean of the three subsequent measurements was used in the study. Moreover, in every woman belonging to group A or B, a microbiological smear for aerobic bacteria culture was taken from the cervical canal during gynecologic examination. In group A, after exclusion of diagnosis of intrauterine infection, intravenous inflow of Fenoterol in dosage range from 0,0035 to $0,005 \mathrm{mg} / \mathrm{min}$ was administered as a tocolytic agent, until the inhibition of uterine contractions. The participants were also given Betamethasone in two $12 \mathrm{mg}$ doses with 24-hour intervals to accelerate fetal lung maturation. 
TABLE 1: General characteristics of the studied population (mean \pm SD).

\begin{tabular}{lcccc}
\hline Parameters & Group A & Group B & Group C & palue \\
\hline Number of women & 41 & 49 & 48 & - \\
Age [years] & $28 \pm 6$ & $30 \pm 7$ & $29 \pm 6$ & NS \\
Gestational age [weeks] & $31 \pm 3$ & $31 \pm 4$ & $39 \pm 1$ & $p=0,0001$ \\
Parity & $2 \pm 1$ & $2 \pm 1$ & $2 \pm 1$ & NS \\
\hline
\end{tabular}

TABLE 2: Inclusion criteria.

\begin{tabular}{|c|c|c|c|}
\hline Group & $\mathrm{A}(n=41)$ & $\mathrm{B}(n=49)$ & $\mathrm{C}(n=48)$ \\
\hline Week of gestation & $22-36$ & $22-36$ & $37-41$ \\
\hline \multirow{4}{*}{ Signs \& symptoms } & $\begin{array}{l}\text { Uterine contractions of the frequency } \\
\geq 4 \text { per } 60 \text { minutes, documented in } \\
\text { CTG record. }\end{array}$ & $\begin{array}{l}\text { Absence of uterine contractions, } \\
\text { documented in CTG records. }\end{array}$ & $\begin{array}{l}\text { Absence of uterine contractions, } \\
\text { documented in CTG records. }\end{array}$ \\
\hline & Bishop score $\geq 4$ & & \\
\hline & & $\begin{array}{l}\text { Rupture of fetal membranes } \\
\text { confirmed with one of the } \\
\text { following: }\end{array}$ & $\begin{array}{l}\text { Rupture of fetal membranes } \\
\text { confirmed with one of the } \\
\text { following: }\end{array}$ \\
\hline & $\begin{array}{l}\text { Cervix length } \leq 25 \mathrm{~mm} \text { documented in } \\
\text { ultrasound scans. }\end{array}$ & $\begin{array}{l}\text { (i) vaginal discharge } \mathrm{pH} \geq 7 \text {, } \\
\text { (ii) positive result of Amni Sure } \\
\text { test, } \\
\text { (iii) positive result of Amni Prom } \\
\text { test. }\end{array}$ & $\begin{array}{l}\text { (i) vaginal discharge } \mathrm{pH} \geq 7 \text {, } \\
\text { (ii) positive result of Amni Sure } \\
\text { test, } \\
\text { (iii) positive result of Amni Prom } \\
\text { test. }\end{array}$ \\
\hline
\end{tabular}

TABLE 3: Coefficients of variation for the assays.

\begin{tabular}{lcr}
\hline \multirow{2}{*}{ Assays } & & Coefficients of variation (CV) \\
& Intra-assay (within-run) [\%] & Interassay (run-to-run) [\%] \\
\hline sRAGE & 4.00 & 7.15 \\
esRAGE & 5.20 & 8.50 \\
\hline
\end{tabular}

Eventually the whole group A was categorized into subgroups by the duration of pregnancy from the diagnosis of threatened premature labor up to delivery, with a seven day cut-off point.

After diagnosis, antibiotic agents were administered in group $\mathrm{B}$ to extend the duration of pregnancy between the rupture of membranes and delivery. Intravenous $2 \mathrm{~g}$ of Ampicilin and $300 \mathrm{mg}$ of Erythromycin every six hours for 48 hours and subsequently oral $500 \mathrm{mg}$ of Amoxycilin every eight hours and $250 \mathrm{mg}$ of Erythromycin every six hours for five days were considered as a standard. These women were also given two $12 \mathrm{mg}$ doses of Betamethasone with 24hour intervals to accelerate fetal lung maturation, avoiding tocolytic agents administration.

Group B was additionally divided into subgroups according to pregnancy duration from the rupture of membranes to delivery, with the cut-off point considered as 24 hours.

The study was approved by the Bioethical Committee of Pomeranian Medical University (KB-0012/121/12).

3.1. Statistical Analysis. The statistical evaluation was performed using Statistica 10,0 PL software for Windows. The distribution of variables was checked using nonparametric W Shapiro-Wilk's test and, according to its results, values were further analyzed. The level of significance $(p)$ was set at less than 0,05 . For the presentation of not normally distributed variables the number of patients $(N)$, values' range (min$\max )$, medians $(\mathrm{Me})$, and the first and third quartile values (Q1-Q3) were included in the descriptive statistics. However, for normally distributed variables' characteristics, the results were presented as number of patients $(N)$, arithmetical mean $(X)$, and standard deviation (SD). To assess the differences between analyzed parameters between two groups the MannWhitney test for unpaired variables was used. We used the ANOVA Kruskall-Wallis test to assess the differences between analyzed parameters between more than two groups. For the statistical analysis of relationship between $X$ and $Y$, correlations' coefficients were estimated using Spearman's test. Receiver operation characteristic (ROC) curve analyses to determine the cut-off point, as well as the predictive value of tests, their sensitivity, specificity, positive and negative predictive values (PPV and NPV, resp.), and accuracy, were analysed.

\section{Results}

The majority of studied parameter distributions deviated from the normal distribution (Shapiro-Wilk test $p>0,05$ ). 
TABLE 4: Descriptive statistics of studies groups by ANOVA Kruskall-Wallis comparison.

\begin{tabular}{lcccccccccccccccc}
\hline \multirow{2}{*}{ Parameters } & \multicolumn{1}{c}{ Group A } & \multicolumn{1}{c}{ - } & \multicolumn{1}{c}{ Group B } & \multicolumn{4}{c}{ Group C } \\
& $N$ & min-max & Q1 & Q3 & Me & $N$ & min-max & Q1 & Q3 & Me & $N$ & $\min -\max$ & Q1 & Q3 & Me & $P$ \\
\hline Age [years] & 41 & $15-41$ & 24 & 32 & 30 & 49 & $16-41$ & 26 & 35 & 31 & 48 & $17-40$ & 25 & 33 & 29 & NS \\
WBC [G/L] & 41 & $3,3-20,0$ & 9,51 & 14,4 & 13,19 & 49 & $8,2-25,4$ & 10,05 & 14,38 & 11,82 & 48 & $8,0-21,0$ & 9,97 & 14,04 & 11,43 & NS \\
CRP [mg/L] & 41 & $0,4-39,5$ & 2,3 & 5,5 & 3,7 & 49 & $0,2-77,3$ & 2,7 & 11,8 & 5,8 & 48 & $0,3-19,0$ & 1,5 & 5,4 & 3,7 & NS \\
Band [\%] & 41 & $63-92$ & 74,2 & 79,4 & 76,8 & 49 & $55-91$ & 66,7 & 80,8 & 71,7 & 48 & $60-91$ & 66,9 & 79,8 & 73,0 & NS \\
sRAGE [pg/mL] & 41 & $128-1686$ & 352 & 787 & 594 & 49 & $48-4872$ & 297 & 775 & 612 & 48 & $77-1787$ & 285 & 887 & 714 & NS \\
esRAGE [pg/mL] & 41 & $230-915$ & 406 & 533 & 490 & 49 & $281-958$ & 483 & 610 & 541 & 48 & $410-1096$ & 497 & 613 & 542 & $\mathbf{0 , 0 0}$ \\
\hline
\end{tabular}

WBC: white blood cells.

CRP: C-reactive protein serum level.

Band: banded neutrophils.

sRAGE: secretory receptors for advanced glycation end products.

esRAGE: endogenous secretory receptors for advanced glycation end products.

Q1: Quartile 1.

Q3: Quartile 3.

Me: median.

$p$ : level of significance.

TABLE 5: Correlations between sRAGE, esRAGE, and biochemical and clinical markers of preterm labor. Groups A and B ( $N=89)$.

\begin{tabular}{|c|c|c|c|c|c|c|c|c|c|}
\hline \multirow{2}{*}{ Correlations } & \multicolumn{2}{|c|}{ Group A } & \multicolumn{2}{|c|}{ Group B } & \multirow{2}{*}{ Correlations } & \multicolumn{2}{|c|}{ Group A } & \multicolumn{2}{|c|}{ Group B } \\
\hline & $R$ & $p$ & $R$ & $p$ & & $R$ & $p$ & $R$ & $p$ \\
\hline esRAGE versus WBC & 0,149 & NS & 0,030 & NS & sRAGE versus WBC & 0,070 & NS & 0,022 & NS \\
\hline esRAGE versus CRP & 0,238 & NS & 0,390 & 0,02 & sRAGE versus CRP & $-0,303$ & NS & $-0,304$ & NS \\
\hline esRAGE versus Band & 0,133 & NS & 0,035 & NS & sRAGE versus Band & $-0,171$ & NS & $-0,179$ & NS \\
\hline esRAGE versus MC & $-0,165$ & NS & $-0,148$ & NS & sRAGE versus MC & $-0,165$ & NS & $-0,177$ & NS \\
\hline esRAGE versus $\mathrm{CxL}$ & $-0,186$ & NS & 0,002 & NS & sRAGE versus $\mathrm{CxL}$ & 0,017 & NS & 0,002 & NS \\
\hline esRAGE versus LT & 0,212 & NS & 0,185 & NS & sRAGE versusLT & 0,422 & 0,001 & 0,413 & 0,004 \\
\hline esRAGE versus GD & 0,045 & NS & 0,069 & NS & sRAGE versus GD & 0,469 & 0,002 & 0,069 & NS \\
\hline esRAGE versus BW & 0,038 & NS & 0,091 & NS & sRAGE versus BW & 0,338 & 0,03 & 0,047 & NS \\
\hline
\end{tabular}

$p$ : level of significance.

$R$ : Spearman's correlation rate.

sRAGE: secretory receptors for advanced glycation end products.

esRAGE: endogenous secretory receptors for advanced glycation end products.

WBC: white blood cells.

CRP: C-reactive protein.

Band: banded neutrophils.

MC: microbial culture from the cervix.

CxL: ultrasound cervical length.

LT: latent time, from PPROM till delivery and from diagnosis of threatened preterm labour till delivery.

GD: gestational age at delivery.

BW: birth weight.

Patients did not differ significantly between study groups in terms of age, white blood cell counts, banded neutrophils, CRP plasma level, and sRAGE concentration. There were significant differences in esRAGE levels found between groups. Table 4 shows the summary of results obtained in each group.

In groups $\mathrm{B}$ and $\mathrm{C}$, higher levels of esRAGE were found compared with group A $(526,315 \pm 129,453 \mathrm{pg} / \mathrm{mL}$ and 576,212 $\pm 136,237 \mathrm{pg} / \mathrm{mL}$ versus $485,918 \pm 133,127 \mathrm{pg} / \mathrm{mL}, p<0,05)$.

Rank correlation was analyzed in A and B groups between the levels of sRAGE and esRAGE and white blood cells count, CRP concentration, banded neutrophils, cervical microbiological smear findings, cervical length in ultrasound examination, neonate birth weight, gestational age at delivery, and latency period after diagnosis. A positive correlation was found in group A between plasma sRAGE concentration and pregnancy duration from diagnosis to delivery $(r=0,422$; $p=0,001)$, neonate birth weight $(r=0,338 ; p=0,03)$, and gestational age at delivery $(r=0,469 ; p=0,002)$. In $\mathrm{B}$ group the latency period from diagnosis to delivery seemed to extend in the presence of increasing sRAGE plasma levels (Table 5).

In the subgroup of pregnancies with latency period extended over seven days, significantly higher concentrations of sRAGE were found, compared with those with latency less than seven days $(\mathrm{Me}=405,923$ versus $744,001 \mathrm{pg} / \mathrm{mL}$; $p=0,004)$. The analysis of area under the ROC curve for sRAGE and latency period revealed the cut-off point for latency duration over seven days as a sRAGE concentration of $726,300 \mathrm{pg} / \mathrm{mL}$, with test specificity 0,947 and sensitivity 0,591 (Figure 1). 

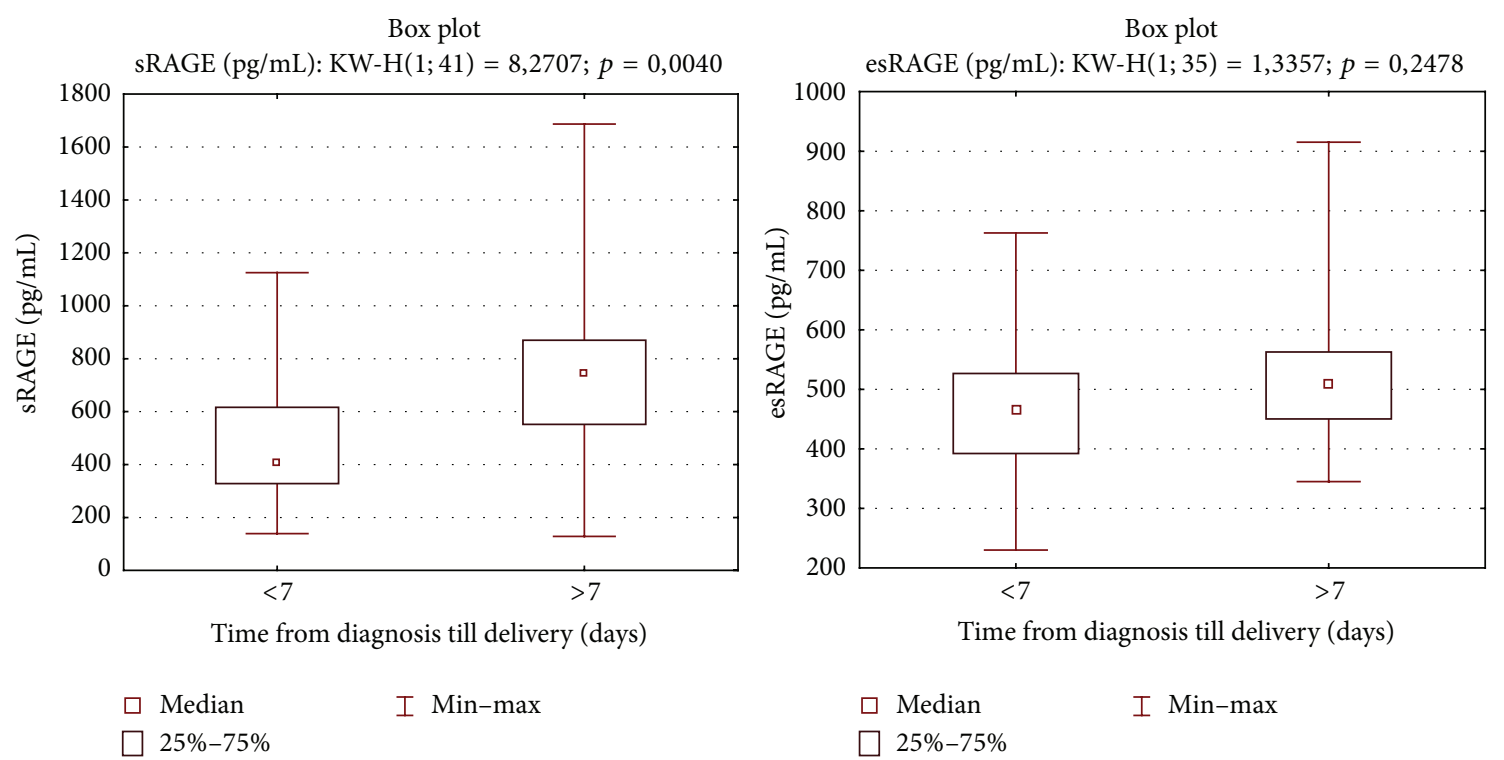

Receiver operating characteristic sRAGE-cut-off point- $726,3 \mathrm{pg} / \mathrm{mL}$
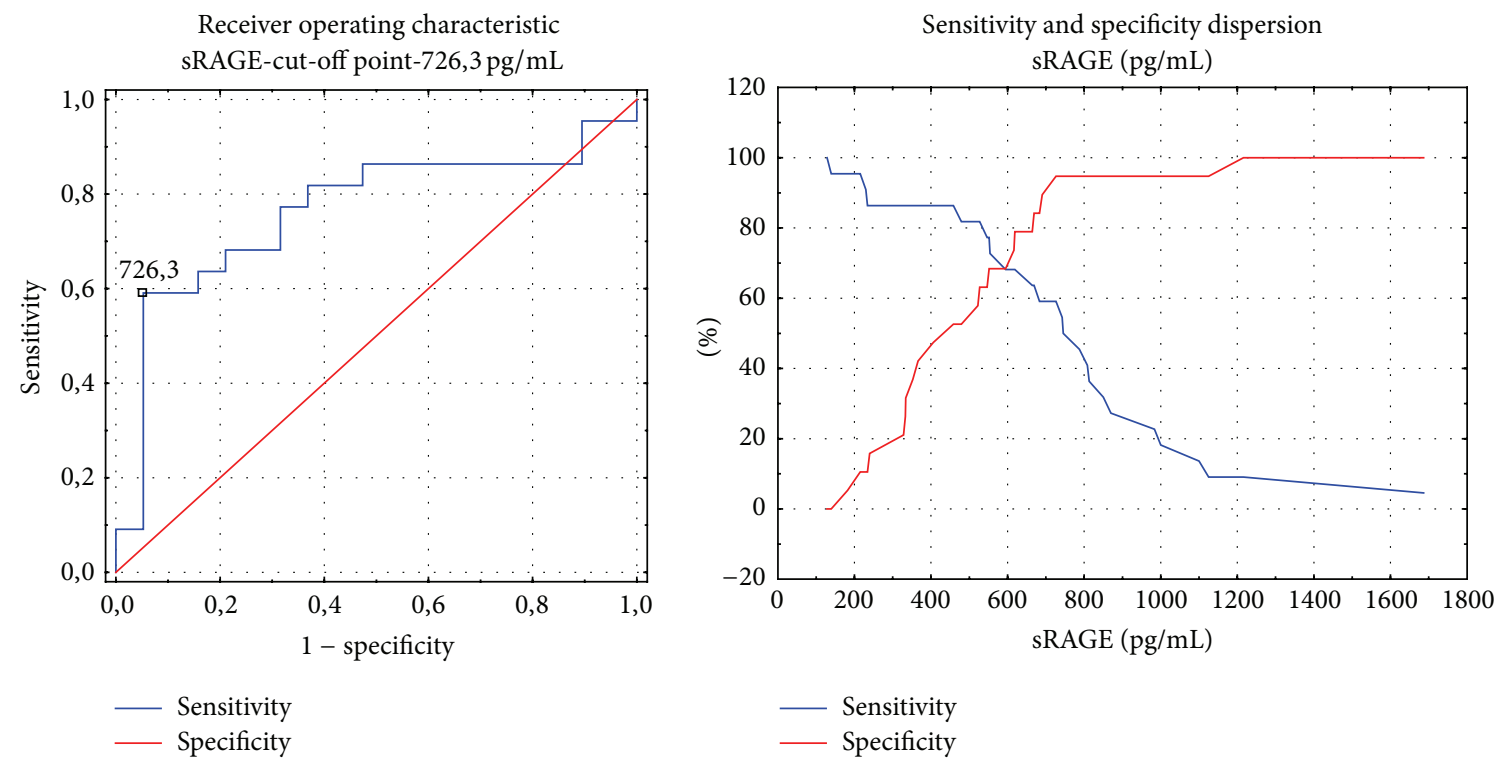

AUC: 0,763

Sensitivity: 0,591

Specificity: 0,947

PPV (positive predictive value): 0,929

NPV (negative predictive value): 0,667

ACC (accuracy): 0,756

FIGURE 1: Group A. sRAGE and esRAGE comparison according to 7-day latent time. Mann-Whitney test; sRAGE ROC curve analysis for latent time.

In group B higher sRAGE levels occurred in women whose latency period from pPROM until delivery was over 24 hours $(\mathrm{Me}=712,05 \mathrm{pg} / \mathrm{mL}$ versus $368,11 \mathrm{pg} / \mathrm{mL} ; p=0,007)$. Both subgroups presented comparable esRAGE concentrations. The analysis of area under the ROC curve for sRAGE and latency period in group B yielded an sRAGE level equal to $265,08 \mathrm{pg} / \mathrm{mL}$ as the cut-off point for latency period over 24 hours, with test specificity 0,591 and sensitivity 0,960 (Figure 2).

\section{Discussion}

5.1. Receptors for Advanced Glycation End Products. The receptors for advanced glycation end products (RAGE) pertain to the group of transmembrane multiligand receptors belonging to the immunoglobulin superfamily, the activation of which is crucial, inter alia, for induction and maintenance of inflammatory response [26-28]. The RAGE is located on the surface of many cell populations, including phagocytes, 
Box plot
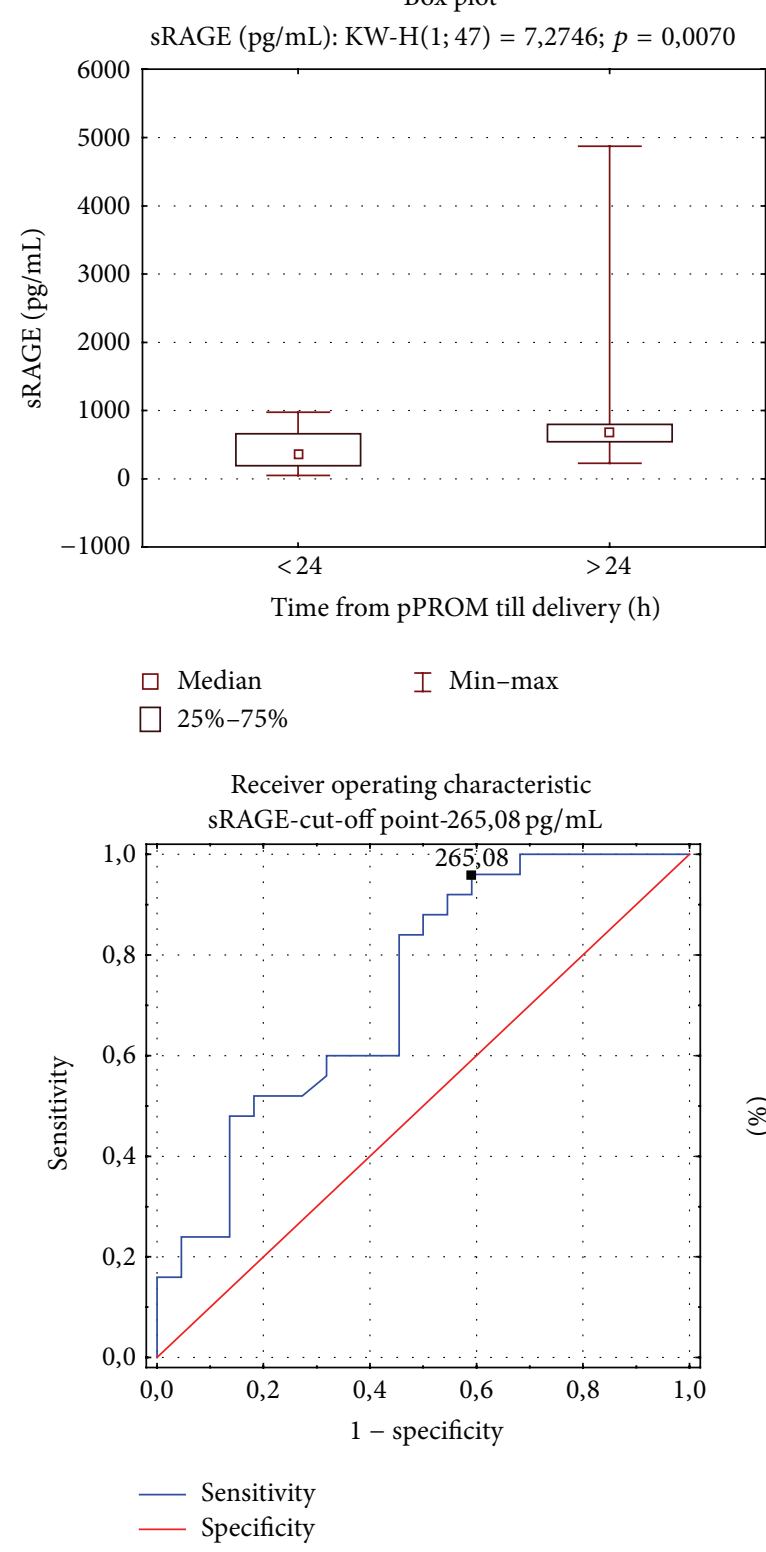

AUC: 0,73

Sensitivity: 0,960

Specificity: 0,591

PPV (positive predictive value): 0,649

NPV (negative predictive value): 0,900

ACC (accuracy): 0,702
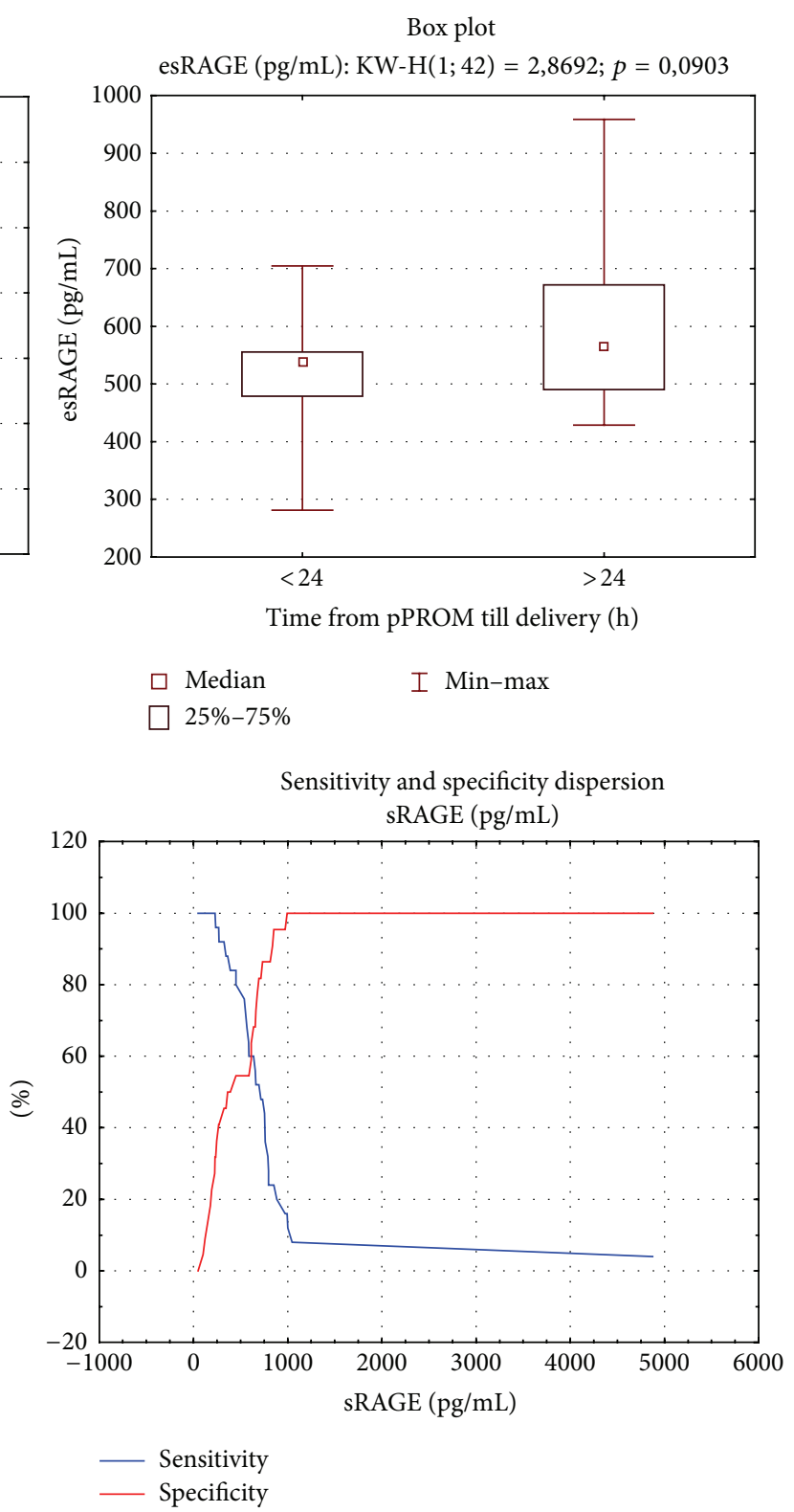

FIGURE 2: Group B. sRAGE and esRAGE comparison according to 24-hour latent time. Mann-Whitney test. sRAGE ROC curve analysis for latent time.

hepatocytes, endothelium, smooth muscles of blood vessel media, nervous system cells, and mesangial cells of the glomeruli [26]. The RAGE determining gene is localized on the 6th chromosome, next to the major histocompatibility complex class III region [29]. This location makes RAGE probable not only to act as a receptor but also to be involved in the reaction to different types of injury [30]. It has been proven that the RAGE gene expression can be induced in response to enhanced cell activation caused by increased concentration of RAGE ligands in case of tissue damage and inflammation [27].

Apart from the native RAGE form, there are some additional, mostly negative, isoforms described in the literature. Negative RAGEs are heterogenic protein groups, capable of binding, inter alia, advanced glycation end products (AGE) and alarmines. Thanks to ligands binding, negative RAGEs inhibit the response mediated by advanced glycation end products and some alarmines and have a protective effect 
on blood vessels against toxic influence of ligand-RAGE complexes [31-33]. The membrane form of the receptor, known as dominating negative RAGE (dnRAGE), can be found on the cell surface. The ligands attached to the receptor concentrate on the cell surface, which results in suppression of the receptor's signal transduction $[28,34]$. The sRAGEligand complexes lose their affinity for heparan sulfate to be released to the blood stream and to be, eventually, captured and degraded in the liver or spleen. A particular type of sRAGE lacking the transmembrane and cytosolic domains is thought to be alternatively spliced and named as the endogenous secretory RAGE (esRAGE) [33].

5.2. The RAGEs and Premature Labor. Prior assumption of the protective influence of negative RAGEs leads to the question whether different levels of receptors' soluble forms in the pregnant can correlate with the prevalence of premature labor, considered both are a sequel of spontaneous uterine contractility or premature rupture of membranes as well. Because the main objective of the study was to analyze a potential role of negative RAGEs in the pathogenesis of preterm labor, sRAGE and esRAGE concentration was assessed in all participants and compared among study groups. There is little research on the evaluation of sRAGE and esRAGE levels in pregnant women suffering from threatened preterm labor and/or premature rupture of membranes. Hájek et al. found sRAGE mean concentration in pregnancy to be about $669 \pm 296 \mathrm{pg} / \mathrm{mL}$ and estimated lower sRAGE concentration in women diagnosed with threatened premature labor than in healthy pregnant women [35]. In our study sRAGE levels were compared reaching, respectively, $594,9,612,9$, and $714,45 \mathrm{pg} / \mathrm{mL}$ in groups $\mathrm{A}, \mathrm{B}$, and $\mathrm{C}$, without significant differences among the groups, which is in contrast with findings of Hájek et al. [35]. Following the quest, Germanová et al. determined sRAGE levels to be the lowest in the 1st and 3rd trimesters of uncomplicated pregnancy, tending to decrease in women diagnosed with preterm labor and/or preeclampsia [36]. The weak point of the study was the small number of participants, amounting to 42 .

In our research the sRAGE concentration was also the lowest the in preterm labor group, but, compared with the other, did not differ significantly, while the analysis and comparison of esRAGE concentration proved remarkable differences among study groups. Women from groups B (pPROM) and C (PROM) had significantly higher levels of esRAGE than those from group A. The question of whether, and in what mechanism, increased concentration of esRAGE is associated with the preterm rupture of membranes should be considered in the near future. The connection between sRAGE and esRAGE plasma levels and the rupture of membranes has not been proven in literature till now, since most of the research concerned the role of amniotic fluid RAGEs concentration in premature labor [37].

Roberto Romero is the leading investigator of RAGEs in the obstetric context. In 2008 he evaluated sRAGE and esRAGE amniotic fluid concentration in categorized groups of the pregnant women: in their 2nd trimester of pregnancy, at term but lacking symptomatic labor, at term in labor, diagnosed with threatened preterm labor with unruptured membranes, and diagnosed with preterm premature rupture of fetal membranes. He assessed receptor concentrations depending on the presence or absence of intrauterine infection in preterm pregnancies, finding that participants with symptoms of labor at term had lower levels of sRAGE, while in women at preterm labor lower sRAGE concentration correlated with intrauterine infection [37]. Taking into account the molecular patterns of RAGEs function in the modulation of inflammatory response, the findings cited above must be regarded as unexpected [38].

Our study focused on calculation of plasma RAGEs concentration only, since we presume that confirmation of association of sRAGE and esRAGE plasma levels with preterm labor would result not only in future research, but above all as an introduction of a new clinical diagnostics tool. The correlation between RAGEs (sRAGE and esRAGE) and other preterm labor markers was evaluated in A and B study groups. The measurement of latency period, from the onset of premature labor symptoms till delivery in group A and from premature rupture of membranes up to delivery in group B, was the particular element of further statistical analysis. The cut-off point was determined at seven days in group A and at 24 hours in group B, which has its practical implication; that is, estimation of latency period in a pregnant women with threatened premature labor for over seven days lets her safely leave the hospital after adequate treatment. There was positive correlation in group A between plasma sRAGE levels and latency period duration, gestational age at delivery, and neonatal birth weight. High values of correlation coefficient for sRAGE plasma concentration and latency $(r=$ $0,42)$ and for sRAGE and gestational age at delivery $(r=0,47)$ became a good reason for analysis of the area under the ROC curve, in order to evaluate the sRAGE plasma level cut-off point at which premature labor occurs later than seven days from the onset of symptoms. We considered sRAGE plasma concentration over $726,3 \mathrm{pg} / \mathrm{mL}$ to be the predictive factor of preterm delivery, with sensitivity 0,591 and specificity 0,947 . The results obtained in our study seem to be consistent with the protective function of negative forms of RAGEs, which has already been proven and described in the literature [3941]. The protective effect of increased sRAGE plasma level was also documented by Bastek et al., who analyzed it in the group of pregnant women $(n=529)$ suffering from threatened preterm labor, from which $39,8 \%$ of the participants gave premature birth. In the last subgroup significantly lower plasma sRAGE concentration was detected $(771,79 \mathrm{pg} / \mathrm{mL})$, compared with those who delivered at term $(948,485 \mathrm{pg} / \mathrm{mL})$. The authors concluded that sRAGE plasma level estimation would be useful as a preterm delivery prognostic marker and its high value can be a favorable prognostic factor. They also evaluated cord blood sRAGE concentration in the infants born to participants of the study, finding higher sRAGE levels correlated with lower occurrence of sepsis in the neonates [42]. After the rupture of membranes in preterm gestation, potential risk of overt intrauterine infection is 
associated with pregnancy prolongation [43, 44]. Increased plasmatic levels of CRP, IL-1, and procalcitonin, as well as observable symptoms, suggest infection development [45, 46]. The diagnosis of overt intrauterine infection is an adverse prognostic factor for premature newborns. From the other point of view, extension of pregnancy duration after preterm rupture of membranes, especially those occurring before 30 weeks of gestation, may increase the chance of proper psychomotor development in preterm infants [47]. There is a requirement of a marker of intrauterine infection onset, indicative of the immediate need for parturition.

In our study group B we analyzed the correlation between RAGEs (sRAGE and esRAGE) plasma levels and latency period from the rupture of membranes till delivery, as well as white blood cell counts, CRP concentration, banded neutrophils percentage, ultrasound cervical length, microbial cervical cultures, gestational age at delivery, and neonatal birth weight. What we found was positive relation between sRAGE concentration and latency period duration and between esRAGE and CRP levels. It can be assumed that a higher sRAGE level in this group reduces the risk of rapid intrauterine infection development. Romero et al. were the only ones in 2012 to publish a scientific report on amniotic fluid sRAGE concentration depending on presence or absence of chorioamnionitis in mature pregnancies. They detected a decrease of sRAGE level accompanying signs and symptoms of intrauterine infection [48]. Although in our study the sRAGE level correlated with duration of latency period after pPROM, it was not associated with WBC, neutrophils percentage in blood smear, or with ultrasound cervical length. We observed a negative trend for sRAGE and CRP concentration $(r=-0,303 ; p=0,056)$. In the literature, only Germanová et al. found strong negative correlation between sRAGE and WBC $(r=-0,47)$ [36]. After having found the association between sRAGE and latency period, using the analysis of the area under the ROC curve, we calculated the cut-off point for sRAGE level over which the latency period exceeded 24 hours. The specificity of the test was 0,59 and its sensitivity reached 0,96 for a sRAGE concentration of $265,08 \mathrm{pg} / \mathrm{mL}$. In the literature on this issue lacks the value of sRAGE level indicating rapid intrauterine infection development following preterm premature rupture of membranes. In preterm pregnancy pPROM can be as well a cause as a consequence of chorioamnionitis. It seems that, in case of pPROM following intrauterine infection, the latency period is reduced to less than 24 hours and sRAGE level is low, while in the opposite case the latency exceeds 24 hours, accompanied by significantly higher sRAGE concentration. Unfortunately, only very few researchers are concerned with the evaluation of different forms of RAGEs in premature labor $[36,37,42,48]$. Positive correlation between esRAGE and CRP seems to prove that every form of RAGE can play a different role in preterm labor pathogenesis. The results obtained in our study, which is partly consistent with the other authors' research, demonstrate the role of DAMPs and many forms of their receptors in the pathogenesis of premature labor. The paucity of the literature on the topic and contradictory results of some studies show the need for future research on the role of RAGEs in preterm labor.

\section{Conclusions}

(1) Higher plasma esRAGE concentration in the pregnant women with the rupture of membranes in mature and premature pregnancy suggests its participation in fetal membranes destruction. There is a need for further study on esRAGE in women after PROM.

(2) The lack of significant association between white blood cell count or neutrophils percentage and sRAGE level shows that the role of the latter is not necessarily connected with intrauterine infection.

(3) High sRAGE concentration can be a favorable prognostic factor in the presence of symptoms of threatened premature labor. There is a need for more research to confirm results of this observation.

(4) High sRAGE plasma concentration in premature gestation complicated by preterm rupture of the membranes seems to delay the development of intrauterine infection. More studies on this topic are necessary to prove our observation.

\section{Conflict of Interests}

The authors declare that there is no conflict of interests regarding the publication of this paper.

\section{References}

[1] R. L. Goldenberg, J. F. Culhane, J. D. Iams, and R. Romero, "Epidemiology and causes of preterm birth," The Lancet, vol. 371, no. 9606, pp. 75-84, 2008.

[2] R. Romero, S. K. Dey, and S. J. Fisher, "Preterm labor: one syndrome, many causes," Science, vol. 345, no. 6198, pp. 760$765,2014$.

[3] N. Vrachnis, N. Vitoratos, Z. Iliodromiti, S. Sifakis, E. Deligeoroglou, and G. Creatsas, "Intrauterine inflammation and preterm delivery," Annals of the New York Academy of Sciences, vol. 1205, pp. 118-122, 2010.

[4] R. Rzepka, A. Torbé, R. Czajka, K. Sebastian, B. Małgorzata, and C. Aneta, "Rapid assessment of the IL-6 cervico-vaginal fluid level in threatening preterm labor," Ginekologia Polska, vol. 80, no. 9, pp. 678-681, 2009.

[5] R. Romero, J. Miranda, T. Chaiworapongsa et al., "A novel molecular microbiologic technique for the rapid diagnosis of microbial invasion of the amniotic cavity and intra-amniotic infection in preterm labor with intact membranes," American Journal of Reproductive Immunology, vol. 71, no. 4, pp. 330-358, 2014.

[6] S. Kwiatkowski, A. Torbé, B. Dołgowska et al., "Isoprostanes 8-iPF2 $\alpha$-III: risk markers of premature rupture of fetal membranes?" Biomarkers, vol. 14, no. 6, pp. 406-413, 2009.

[7] C. A. Combs, M. Gravett, T. J. Garite et al., "Amniotic fluid infection, inflammation, and colonization in preterm labor with intact membranes," American Journal of Obstetrics \& Gynecology, vol. 210, no. 2, pp. 125-128, 2014.

[8] Z. Shahshahan, L. Hashemi, and O. Rasouli, "Maternal serum interleukin 6 and 8 and C-reactive protein in predicting the tocolytic therapy in preterm labor," Journal of Research in Medical Sciences, vol. 19, no. 6, pp. 537-541, 2014. 
[9] P. Chaemsaithong, R. Romero, S. J. Korzeniewski et al., "A point of care test for the determination of amniotic fluid interleukin6 and the chemokine CXCL-10/IP-10," The Journal of MaternalFetal \& Neonatal Medicine, 2014.

[10] G. Luo, V. M. Abrahams, S. Tadesse et al., "Progesterone inhibits basal and TNF-alpha-induced apoptosis in fetal membranes: a novel mechanism to explain progesterone-mediated prevention of preterm birth," Reproductive Sciences, vol. 17, no. 6, pp. 532539,2010

[11] B. C. Timmons, J. Reese, S. Socrate et al., "Prostaglandins are essential for cervical ripening in LPS-Mediated preterm birth but not term or antiprogestin-driven preterm ripening," Endocrinology, vol. 155, no. 1, pp. 287-298, 2014.

[12] J. J. Oppenheim, P. Tewary, G. de la rosa, and D. Yang, "Alarmins initiate host defense," Advances in Experimental Medicine and Biology, vol. 601, pp. 185-194, 2007.

[13] H. E. Harris and A. Raucci, "Alarmin(g) news about danger: workshop on innate danger signals and HMGB1," EMBO Reports, vol. 7, no. 8, pp. 774-778, 2006.

[14] G. H. Goodwin, C. Sanders, and E. W. Johns, "A new group of chromatin associated proteins with a high content of acidic and basic amino acids," European Journal of Biochemistry, vol. 38, no. 1, pp. 14-19, 1973.

[15] R. M. Vabulas, P. Ahmad-Nejad, S. Ghose, C. J. Kirschning, R. D. Issels, and H. Wagner, "HSP70 as endogenous stimulus of the toll/interleukin-1 receptor signal pathway," Journal of Biological Chemistry, vol. 277, no. 17, pp. 15107-15112, 2002.

[16] A. M. Schmidt, S. D. Yan, S. F. Yan, and D. M. Stern, "The biology of the receptor for advanced glycation end products and its ligands," Biochimica et Biophysica Acta-Molecular Cell Research, vol. 1498, no. 2-3, pp. 99-111, 2000.

[17] T. Noguchi, T. Sado, K. Naruse et al., "Evidence for activation of toll-like receptor and receptor for advanced glycation end products in preterm birth," Mediators of Inflammation, vol. 2010, Article ID 490406, 10 pages, 2010.

[18] M.-P. Wautier, O. Chappey, S. Corda, D. M. Stern, A. M. Schmidt, and J.-L. Wautier, "Activation of NADPH oxidase by AGE links oxidant stress to altered gene expression via RAGE," The American Journal of Physiology-Endocrinology and Metabolism, vol. 280, no. 5, pp. E685-E694, 2001.

[19] A. C. Ledoux and N. D. Perkins, "NF- $\kappa$ B and the cell cycle," Biochemical Society Transactions, vol. 42, no. 1, pp. 76-81, 2014.

[20] A. M. Schmidt, O. Hori, J. X. Chen et al., "Advanced glycation endproducts interacting with their endothelial receptor induce expression of vascular cell adhesion molecule-1 (VCAM-1) in cultured human endothelial cells and in mice: a potential mechanism for the accelerated vasculopathy of diabetes," The Journal of Clinical Investigation, vol. 96, no. 3, pp. 1395-1403, 1995.

[21] K. Fujisawa, N. Katakami, H. Kaneto et al., "Circulating soluble RAGE as a predictive biomarker of cardiovascular event risk in patients with type 2 diabetes," Atherosclerosis, vol. 227, no. 2, pp. 425-428, 2013.

[22] G. Daffu, C. H. del Pozo, K. M. O'Shea, R. Ananthakrishnan, R. Ramasamy, and A. M. Schmidt, "Radical roles for RAGE in the pathogenesis of oxidative stress in cardiovascular diseases and beyond," International Journal of Molecular Sciences, vol. 14, no. 10, pp. 19891-19910, 2013.

[23] N. Grossin, M.-P. Wautier, T. Meas, P.-J. Guillausseau, P. Massin, and J.-L. Wautier, "Severity of diabetic microvascular complications is associated with a low soluble RAGE level," Diabetes \& Metabolism, vol. 34, no. 4, pp. 392-395, 2008.
[24] F. Piarulli, A. Lapolla, E. Ragazzi et al., "Role of endogenous secretory RAGE (esRAGE) in defending against plaque formation induced by oxidative stress in type 2 diabetic patients," Atherosclerosis, vol. 226, no. 1, pp. 252-257, 2013.

[25] K. A. Moy, L. Jiao, N. D. Freedman et al., "Soluble receptor for advanced glycation end products and risk of liver cancer," Hepatology, vol. 57, no. 6, pp. 2338-2345, 2013.

[26] R. Ramasamy, S. F. Yan, K. Herold, R. Clynes, and A. M. Schmidt, "Receptor for advanced glycation end productsfundamental roles in the inflammatory response: Winding the way to the pathogenesis of endothelial dysfunction and atherosclerosis," Annals of the New York Academy of Sciences, vol. 1126, pp. 7-13, 2008.

[27] G. Basta, G. Lazzerini, M. Massaro et al., "Advanced glycation end products activate endothelium through signaltransduction receptor RAGE: a mechanism for amplification of inflammatory responses," Circulation, vol. 105, no. 7, pp. 816$822,2002$.

[28] Q. Ding and J. N. Keller, "Evaluation of rage isoforms, ligands, and signaling in the brain," Biochimica et Biophysica ActaMolecular Cell Research, vol. 1746, no. 1, pp. 18-27, 2005.

[29] K. Sugaya, T. Fukagawa, K.-I. Matsumoto et al., “Three genes in the human MHC class III region near the junction with the class II: gene for receptor of advanced glycosylation end products, PBX2 homeobox gene and a notch homolog, human counterpart of mouse mammary tumor gene int-3," Genomics, vol. 23, no. 2, pp. 408-419, 1994.

[30] A. Rojas and M. A. Morales, "Advanced glycation and endothelial functions: a link towards vascular complications in diabetes," Life Sciences, vol. 76, no. 7, pp. 715-730, 2004.

[31] A. Bierhaus, S. Schiekofer, M. Schwaninger et al., "Diabetesassociated sustained activation of the transcription factor nuclear factor- $\kappa$ B," Diabetes, vol. 50, no. 12, pp. 2792-2808, 2001.

[32] A. Bierhaus, D. M. Stern, and P. P. Nawroth, "RAGE in inflammation: a new therapeutic target?" Current Opinion in Investigational Drugs, vol. 7, no. 11, pp. 985-991, 2006.

[33] L. E. Hanford, J. J. Enghild, Z. Valnickova et al., "Purification and characterization of mouse soluble receptor for advanced glycation end products (sRAGE)," The Journal of Biological Chemistry, vol. 279, no. 48, pp. 50019-50024, 2004.

[34] H. Yonekura, Y. Yamamoto, S. Sakurai et al., "Novel splice variants of the receptor for advanced glycation end-products expressed in human vascular endothelial cells and pericytes, and their putative roles in diabetes-induced vascular injury," Biochemical Journal, vol. 370, no. 3, pp. 1097-1109, 2003.

[35] Z. Hájek, A. Germanová, M. Koucký et al., "Detection of fetomaternal infection/inflammation by the soluble receptor for advanced glycation end products (sRAGE): results of a pilot study," Journal of Perinatal Medicine, vol. 36, no. 5, pp. 399-404, 2008.

[36] A. Germanová, A. Muravská, M. Jáchymová et al., "Receptor for advanced glycation end products (RAGE) and glyoxalase I gene polymorphisms in pathological pregnancy," Clinical Biochemistry, vol. 45, no. 16-17, pp. 1409-1414, 2012.

[37] R. Romero, J. Espinoza, S. Hassan et al., "Soluble receptor for advanced glycation end products (sRAGE) and endogenous secretory RAGE (esRAGE) in amniotic fluid: modulation by infection and inflammation," Journal of Perinatal Medicine, vol. 36, no. 5, pp. 388-398, 2008.

[38] R. Rzepka, B. Dołęgowska, A. Rajewska, and S. Kwiatkowski, "On the significance of new biochemical markers for the 
diagnosis of premature labour," Mediators of Inflammation, vol. 2014, Article ID 251451, 8 pages, 2014.

[39] C. M. Rebholz, B. C. Astor, M. E. Grams et al., "Association of plasma levels of soluble receptor for advanced glycation end products and risk of kidney disease: the atherosclerosis risk in communities study," Nephrology Dialysis Transplantation, vol. 30, no. 1, pp. 77-83, 2015.

[40] L. He, H. Bao, J. Xue et al., "Circulating soluble advanced glycation end product is inversely associated with the significant risk of developing cancer: evidence from a meta-analysis," Tumor Biology, vol. 35, no. 9, pp. 8749-8755, 2014.

[41] K. Prasad, "Low levels of serum soluble receptors for advanced glycation end products, biomarkers for disease state: myth or reality," International Journal of Angiology, vol. 23, no. 1, pp. 1116, 2014.

[42] J. A. Bastek, A. G. Brown, M. N. Foreman et al., "The soluble receptor for advanced glycation end products can prospectively identify patients at greatest risk for preterm birth," The Journal of Maternal-Fetal \& Neonatal Medicine, vol. 25, no. 9, pp. 17621768, 2012.

[43] E. A. S. Clark and M. Varner, "Impact of preterm PROM and its complications on long-term infant outcomes," Clinical Obstetrics and Gynecology, vol. 54, no. 2, pp. 358-369, 2011.

[44] S. L. Buchanan, C. A. Crowther, K. M. Levett, P. Middleton, and J. Morris, "Planned early birth versus expectant management for women with preterm prelabour rupture of membranes prior to 37 weeks' gestation for improving pregnancy outcome," Cochrane Database of Systematic Reviews, no. 3, Article ID CD004735, 2010.

[45] S. Škrablin, H. Lovrić, V. Banović, S. Kralik, A. Dijaković, and D. Kalafatić, "Maternal plasma interleukin-6, interleukin-1 $\beta$ and $\mathrm{C}$-reactive protein as indicators of tocolysis failure and neonatal outcome after preterm delivery," Journal of Maternal-Fetal and Neonatal Medicine, vol. 20, no. 4, pp. 335-341, 2007.

[46] E. Hatzidaki, D. Gourgiotis, A. Manoura et al., "Interleukin-6 in preterm premature rupture of membranes as an indicator of neonatal outcome," Acta Obstetricia et Gynecologica Scandinavica, vol. 84, no. 7, pp. 632-638, 2005.

[47] A. Denzler, T. Burkhardt, G. Natalucci, and R. Zimmermann, "Latency after preterm prelabor rupture of the membranes: increased risk for periventricular leukomalacia," Journal of Pregnancy, vol. 2014, Article ID 874984, 7 pages, 2014.

[48] R. Romero, T. Chaiworapongsa, Z. Alpay Savasan et al., "Clinical chorioamnionitis is characterized by changes in the expression of the alarmin HMGB1 and one of its receptors, sRAGE," Journal of Maternal-Fetal and Neonatal Medicine, vol. 25, no. 6, pp. 558-567, 2012. 


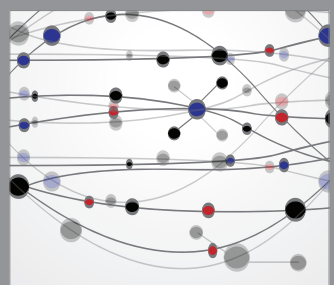

The Scientific World Journal
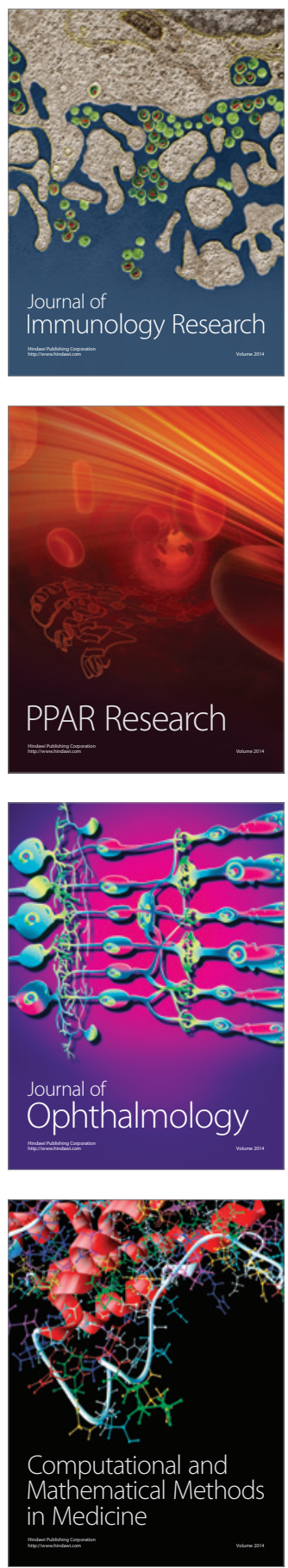

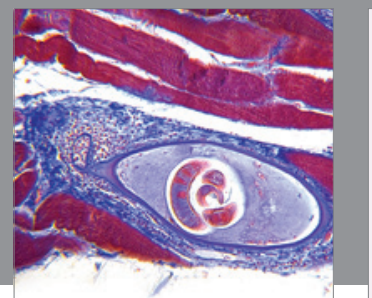

Gastroenterology

Research and Practice
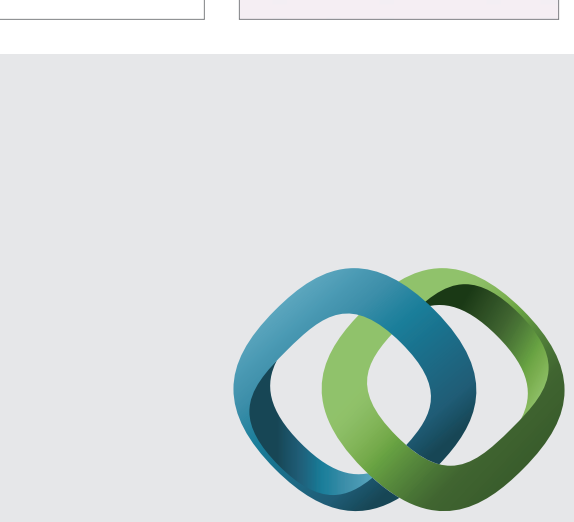

\section{Hindawi}

Submit your manuscripts at

http://www.hindawi.com
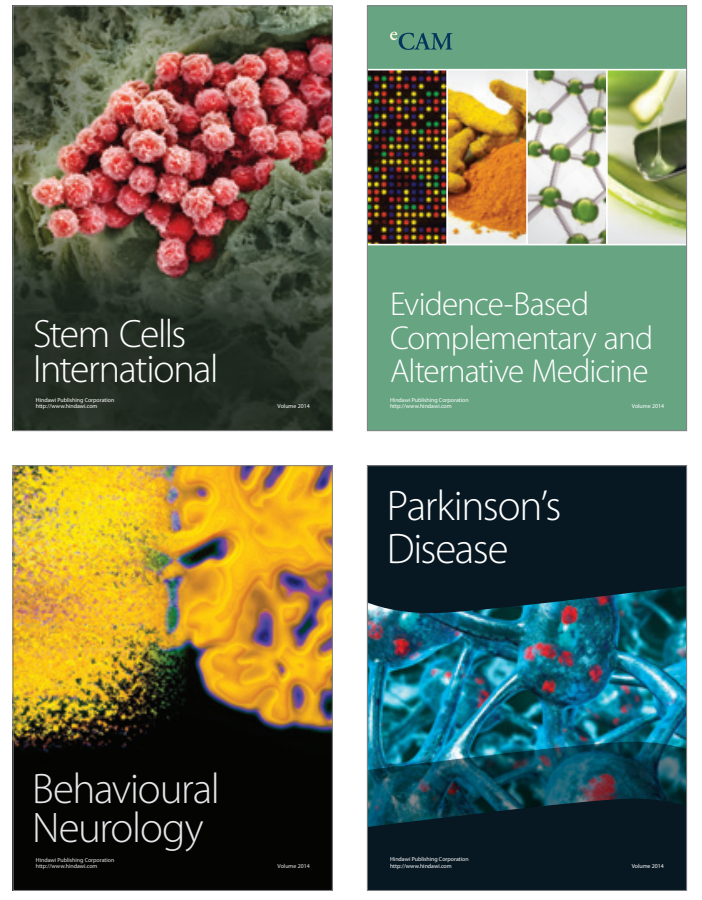
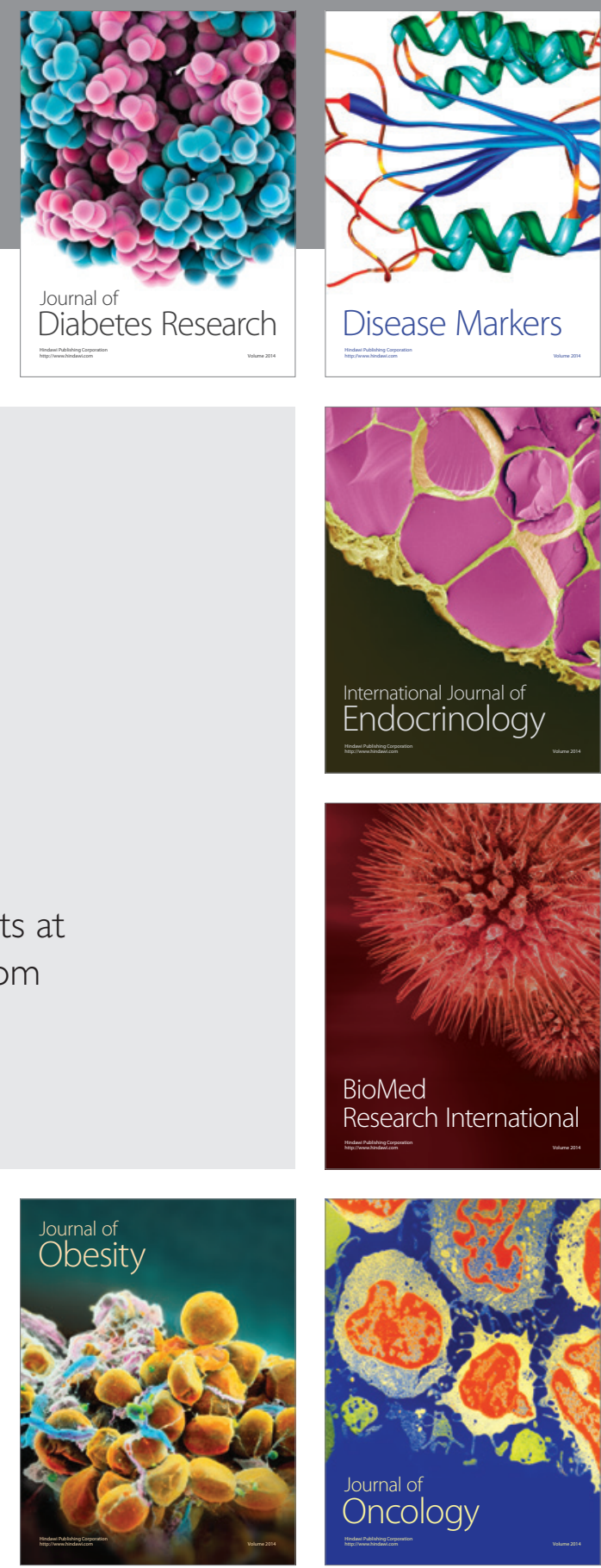

Disease Markers
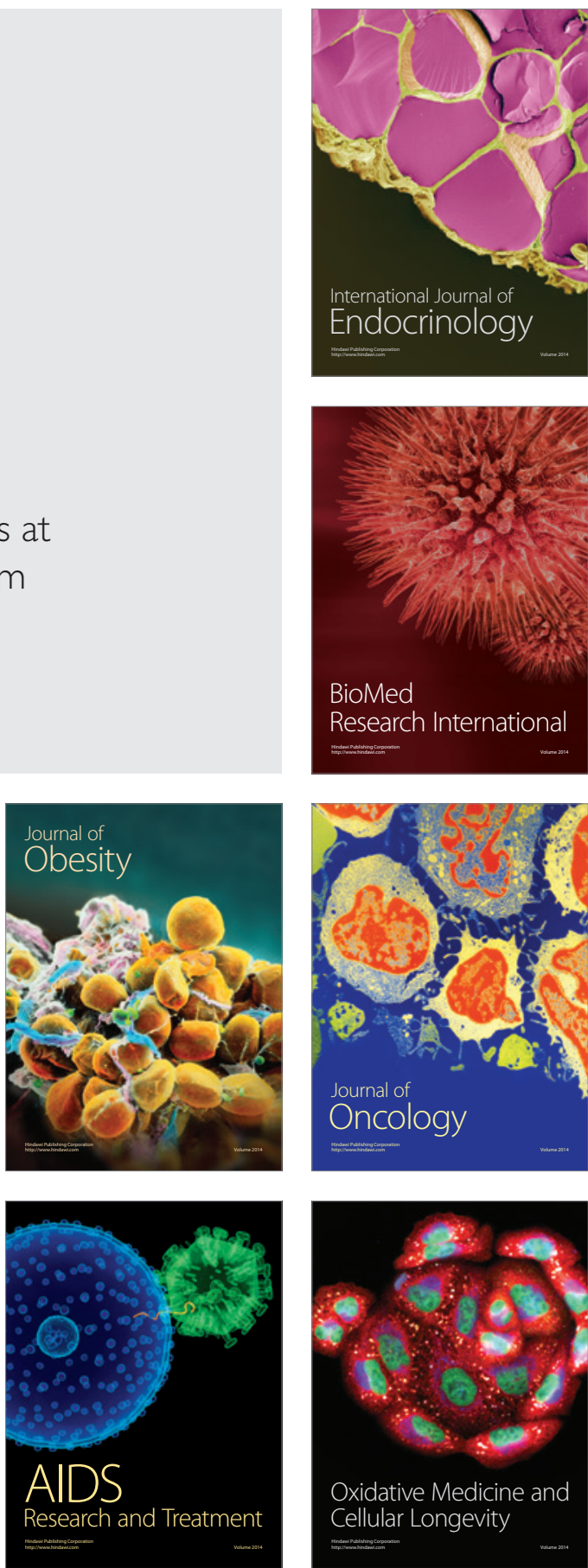